\title{
EMBEDDED FORMULATION OF PRESTRESSED TENDON IN 3D - BRICK ELEMENT
}

\author{
Dr. Mohamad N. Mahmood \\ Assistant Professor
}

Ayad, B. Behnam

Assistant Lecturer

University of Mosul- College of Engineering

\begin{abstract}
In the present work a formulation of the reinforced bars and prestressed tendons embedded in the brick element is developed and used for the nonlinear analysis of reinforced-prestressed concrete beams. The reinforcement and prestressing bars are represented by an axial 3 nodded bar elements embedded into the 20 nodded isoparametric brick concrete element. Perfect bond is assumed between concrete and prestressing steel bars (or tendons) such that displacements and strains of the bars are assumed to be compatible with those of the concrete element. To verify the applicability of the model two prestressed beams are analyzed and the numerical results show a good agreement with the experimental one.
\end{abstract}

Keywords: Brick element, Embedded bar, Finite element, Nonlinear analysis, Prestressed concrete.

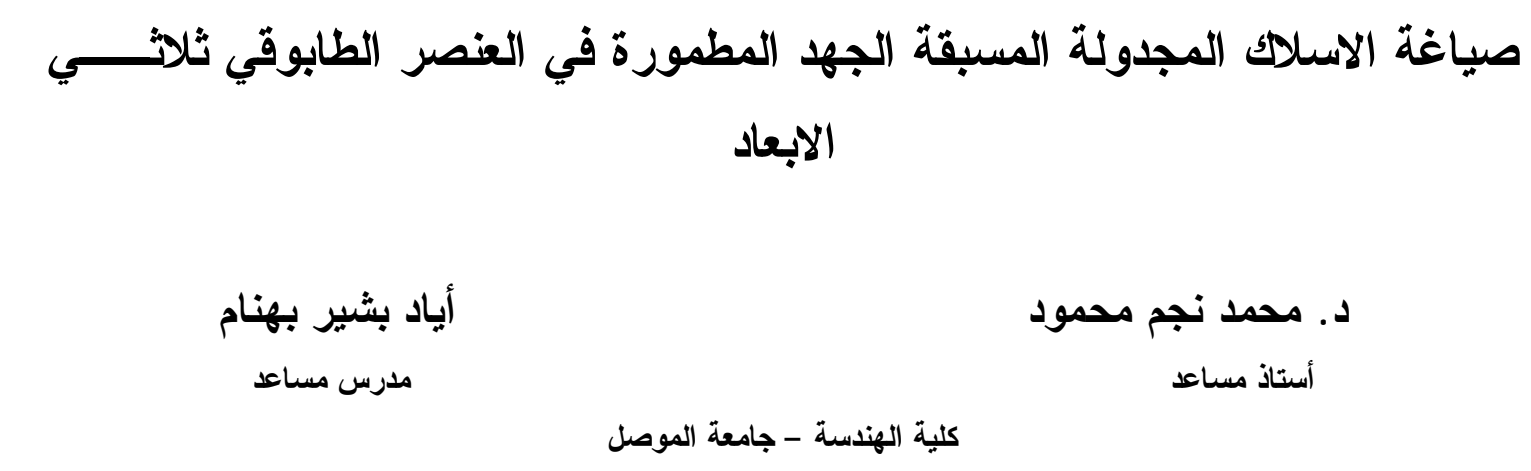

\section{الخلاصة}

يتضمن البحث الحالي وضع صياغة للأسلاك المجدولة المسبقة الجه وقضبان حديد التسليح المطمورة في العنصر الطابوقي لغرض استخدامها في التحليل غير الخطي للعتبات الخرسانية المسلحة المسبقة الجهد. تم تمثيـلـل

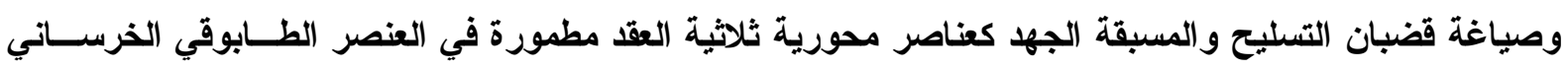
الموحد المعلمية ذات 20 عقدة. اعتمد في الصياغة على فرضية الترابط التام بين القضبان والخرسانة بافتراض حالة

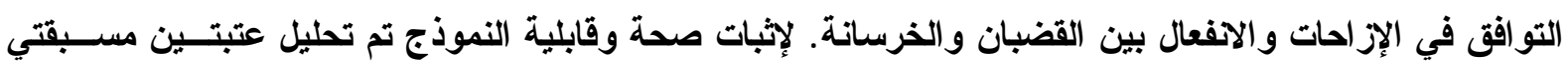
الجه وأظهرت نتائج التحليل توافقاً جيداً مع النتائج العملية. 


\section{Introduction:}

The nonlinear analysis of reinforced or prestressed concrete structures requires an efficient modeling that takes into account the stiffness contribution of the steel bars and prestressing tendons to the structural equilibrium equations. This contribution should not only consider the prestressing forces carried out by the bars, but it should also include the tendon stiffness. The first formulation of the embedded bar to model the reinforcement bars in the nonlinear analysis of axisymmetric concrete structures was presented by Phillips and Zienkiewicz [1] in 1976. Krishnamoorthy and Panneerselvam [2] model the reinforcement bar by embedded two nodes bar elements in the plane stress concrete elements that were used in the nonlinear analysis of reinforced concrete framed structures. Elwi and Hurdy [3] represented the reinforcing bars by using three nodes bar element embedded in plane stress concrete elements.

Mahmood [4] developed an embedded bar model to idealize the steel bar having arbitrary geometry and randomly located within the domain of the concrete shell element. The main emphases of the present work is to develop a generalized model for the analysis of prestressed concrete beams, using a three-dimensional brick elements with embedded-curved tendons placed at any orientation and location within the solid brick element which enable the modeling of prestressing tendons at any eccentricity from the neutral axis of the beam and at any orientation.

\section{Finite Element Model:}

The following simplifying assumptions have been made in considering the prestressing effects:

There is a perfect bond between steel and concrete.

The time dependent losses of prestressing forces such as losses due to creep and shrinkage of concrete are neglected.

The 20 nodded isoparamatric brick element is used to represent the concrete. The stiffness matrix is derived based on the standard displacement function as follows[5]:

$$
[K]_{C}=\int_{-1}^{1} \int_{-1}^{1} \int_{-1}^{1}[B]^{T} \cdot[D] \cdot[B] \cdot|J| d \zeta d \eta d \xi
$$

where $[B]$ is the strain-displacement matrix and $|J|$ is the determinant of Jacobian matrix.

\section{Embedded Bar Formulation:}

The present formulation is based on full strain compatibility between steel and concrete by assuming perfect bond between steel and concrete. To define the geometry of embedded bar, a three nodded bar elements are used with known global nodal coordinates as shown in Fig. (1) and these nodal coordinates can be written for node $(i)$ of element $(e)$ as:

$$
X_{i}^{e}=\left\{\begin{array}{c}
x_{e i} \\
y_{e i} \\
z_{e i}
\end{array}\right\}
$$




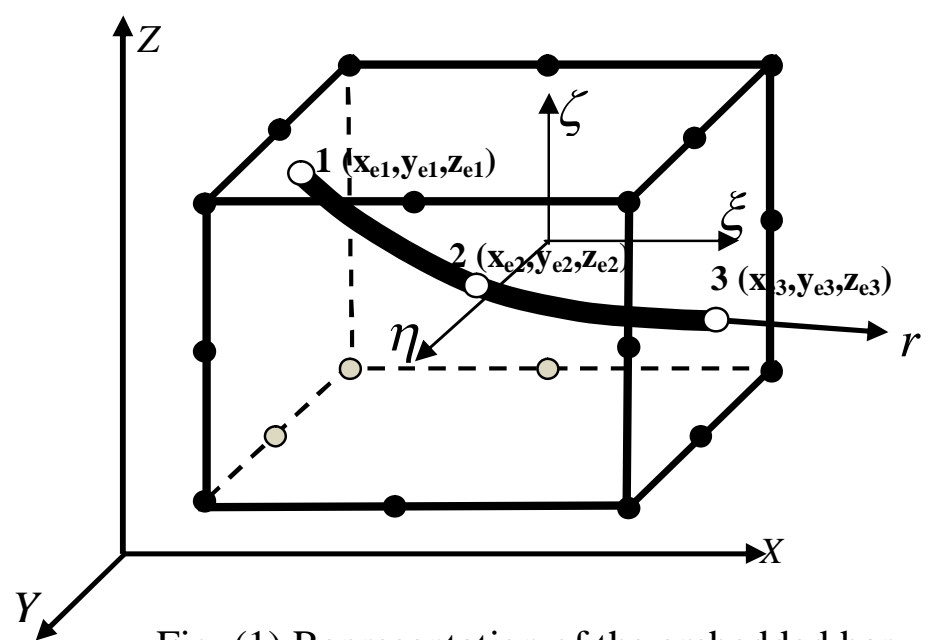

Fig. (1) Representation of the embedded bar.

The interpolation function $\left(M_{i}\right)$ for each node of the embedded bar can be derived by using Lagrange interpolation [5] as:

$M_{1}=0.5 r(r-1)$

$M_{2}=1-r^{2}$

$M_{3}=0.5 r(r+1)$

Where $r$ is a natural coordinate for the embedded bar element with values range from (-1) at node 1 to $(+1)$ at node 3 with node 2 falling at the center of the element. These interpolation functions can be used to evaluate the global coordinates at any point ( $\mathrm{p}$ ) along the bar as:

$X_{p}=\left\{\begin{array}{c}x_{p} \\ y_{p} \\ z_{p}\end{array}\right\}=\sum_{i=1}^{3} M_{i} \cdot X_{i}=\sum_{i=1}^{3} M_{i} \cdot\left\{\begin{array}{l}x_{e i} \\ y_{e i} \\ z_{e i}\end{array}\right\}$

For the same point (p) in the brick element domain with the known global coordinates as determined in the previous equation, the isoparamatric inverse mapping is required to define the natural coordinates $(\xi, \eta, \zeta)$ of that point within the brick element. The ordinary mapping of any point (p) within the 20 nodded brick element having the natural coordinates $(\xi, \eta, \zeta)$ may be written as:

$$
X_{p}=\sum_{i=1}^{20} N_{i}(\xi, \eta, \zeta)^{*} X_{i}
$$

Where $\left(N_{i}\right),\left(X_{i}\right)$ are the shape function and global coordinates $(\mathrm{x}, \mathrm{y}, \mathrm{z})$ of the brick element corresponding to node $(i)$. The inverse mapping involves a system of nonlinear equations. Elwi and Hurdy [3] adopted an iterative approach of inverse mapping for the plane stress element and the same approach was used by Mahmood [4] in the formulation of embedded bar in the general shell element. In the present work, the same procedure is generalized for 
the three dimensions brick element. The iterative approach is based on the fact that the natural coordinates $(\xi, \eta, \zeta)$ are the roots of the nonlinear system.

$$
\{f(\xi, \eta, \zeta)\}=\left\{\begin{array}{l}
x_{p} \\
y_{p} \\
z_{p}
\end{array}\right\}-\left\{\begin{array}{l}
\sum_{i=1}^{20} N_{i}(\xi, \eta, \zeta) \cdot x_{i} \\
20 \\
\sum_{i=1} N_{i}(\xi, \eta, \zeta) \cdot y_{i} \\
20 \\
\sum_{i=1} N_{i}(\xi, \eta, \zeta) \cdot z_{i}
\end{array}\right\}
$$

And the roots $(\xi, \eta, \zeta)$ must satisfy the condition $\{f(\xi, \eta, \zeta)\}=0$.

Using Newton-Raphson iterative scheme, the solution after $(j+1)$ iterations may be written as:

$$
\left\{\begin{array}{l}
\xi \\
\eta \\
\zeta
\end{array}\right\}^{j+1}=\left\{\begin{array}{l}
\xi \\
\eta \\
\zeta
\end{array}\right\}^{j}-\left\{\begin{array}{l}
\Delta \xi \\
\Delta \eta \\
\Delta \zeta
\end{array}\right\}
$$

Where:

$$
\left\{\begin{array}{l}
\Delta \xi \\
\Delta \eta \\
\Delta \zeta
\end{array}\right\}=[J]_{j}^{-1} \cdot\left[\begin{array}{l}
\sum_{i=1}^{20} N_{i}\left(\xi_{j}, \eta_{j}, \zeta_{j}\right) \cdot X_{i} \\
\sum_{i=1}^{20} N_{i}\left(\xi_{j}, \eta_{j}, \zeta_{j}\right) \cdot Y_{i} \\
\sum_{i=1}^{20} N_{i}\left(\xi_{j}, \eta_{j}, \zeta_{j}\right) \cdot Z_{i}
\end{array}\right]
$$

Where $[J]_{j}$ represent the Jacobin matrix at the sampling point $(p)$ along the embedded bar having natural coordinates $\left(\xi_{j}, \eta_{j}, \zeta_{j}\right)$ at the end of $\mathrm{j}^{\text {th }}$ iteration. To start the iterations, initial values of the natural coordinates $(\xi, \eta, \zeta)$ have to be guessed. Convergence is assumed to occur when the difference in each of the three components $(\Delta \xi, \Delta \eta, \Delta \zeta)$ between two successive iterations is less than $\left(10^{-7}\right)$. The contribution of the stiffness matrix of the embedded bar $[K]_{e}$ to that of the parent brick concrete element is calculated by:

$$
[K]_{e}=\int_{v o l} \underline{[B]}^{T} \cdot[D e]^{\prime \prime} \cdot \underline{[B]} \cdot d \Omega
$$

Where $[B]$ is the strain displacement matrix of order $(3 \mathrm{xm}), \mathrm{m}$ is the total degrees of freedom of the brick element [equal to 60 for the 20 nodes brick element]. Integration of equation (9) is carried out using 3 points Gauss quadrature rule having the natural coordinates $(\xi, \eta, \zeta)$ which are determined using the inverse mapping corresponding to the global coordinates $\left(\mathrm{x}_{\mathrm{p}}, \mathrm{y}_{\mathrm{p}}, \mathrm{z}_{\mathrm{p}}\right)$ as explain in equations (2-8). The integral over the domain at each Gauss point is evaluated as:

$$
\int_{\text {vol }} \ldots . . . . d \Omega=\int_{-1}^{+1} \ldots . . . A A_{e} \cdot \mid \underline{|J|} \cdot d r
$$


Where $\left(A_{\boldsymbol{e}}\right)$ is the cross sectional area of the embedded bar and $|\underline{J}|$ is the determinate of the Jacobin vector at the Gauss point of the embedded bar which is determined from the relation:

$$
\underline{[J]}=\left\{\begin{array}{l}
\frac{\partial x}{\partial r} \\
\frac{\partial y}{\partial r} \\
\frac{\partial z}{\partial r}
\end{array}\right\}=\sum_{i=1}^{3} \frac{\partial M_{i}}{\partial r} \cdot\left\{\begin{array}{c}
x_{e i} \\
y_{e i} \\
z_{e i}
\end{array}\right\}
$$

Where $x_{e i}, y_{e i}, z_{e i}$ are the global coordinates of node $i$ of the embedded bar. While the determinate is determined as:

$$
\underline{|J|}=\sqrt{\left(\frac{\partial x}{\partial r}\right)^{2}+\left(\frac{\partial y}{\partial r}\right)^{2}+\left(\frac{\partial z}{\partial r}\right)^{2}}
$$

At each Gauss point of the embedded bar the elasticity matrix in the local coordinates of the bar element is defined as:

$[D e]^{\prime}=\left[\begin{array}{ccc}E_{S} & 0 & 0 \\ 0 & 0 & 0 \\ 0 & 0 & 0\end{array}\right]$

Where $E_{\mathrm{s}}$ is the elastic (or elasto-plastic) modulus of the steel bar as the case may be. This matrix has to be transformed to the global coordinates by the relation:

$$
[D e]^{\prime \prime}=\left[T_{e}\right]^{T} \cdot[D e]^{\prime} \cdot\left[T_{e}\right]
$$

Where $[\mathrm{Te}]$ is the transformation matrix defined as:

$$
\begin{aligned}
& {\left[T_{e}\right]=\left[\begin{array}{ccc}
c c & s s & c s \\
s s & c c & -c s \\
-2 c s & 2 c s & c c-s s
\end{array}\right]} \\
& c c=\cos ^{2} \beta_{e} \\
& s s=\sin ^{2} \beta_{e} \\
& c s=\cos \beta_{e} \cdot \sin \beta_{e}
\end{aligned}
$$

In which $\beta e$ is the angle between the tangent of the bar (at the gauss point along the bar) and either the global $\mathrm{X}$ or $\mathrm{Y}$ axis depending on the orientation of the bar as follows:

When the bar falls in a plane parallel to the $\mathrm{X}-\mathrm{Z}$ plane the angle evaluated as:

$$
\beta_{e}=\tan ^{-1}\left(\frac{\partial z^{\prime}}{\partial r}\right) /\left(\frac{\partial x^{\prime}}{\partial r}\right)
$$

Otherwise if the bar falls in a plane parallel to the Y-Z plane the angle evaluated as: 
$\beta_{e}=\tan ^{-1}\left(\frac{\partial z^{\prime}}{\partial r}\right) /\left(\frac{\partial y^{\prime}}{\partial r}\right)$

Components of the strain at any Gauss point of the embedded bar are determined as:

$\{\varepsilon\}=\left\{\begin{array}{c}\varepsilon_{x} \\ \varepsilon_{z} \\ \gamma_{x z}\end{array}\right\}=[B] \cdot\{a\}$

Where $\{a\}$ is the nodal displacement vector of the brick element. Similarly the stresses at the same point are determined as:

$$
\{\sigma\}=\left\{\begin{array}{c}
\sigma_{x} \\
\sigma_{z} \\
\tau_{x z}
\end{array}\right\}=[D e]^{\prime \prime} \cdot\{\varepsilon\}
$$

The strain $\left(\varepsilon_{r}\right)$ and stress $\left(\sigma_{r}\right)$ along the axis of the embedded bar at any Gauss point when the bar falling in plane parallel to $\mathrm{X}-\mathrm{Z}$ plane, are determined as:

$$
\begin{aligned}
& \varepsilon_{r}=\varepsilon_{x} \cdot \cos ^{2} \beta_{e}+\varepsilon_{z} \cdot \sin ^{2} \beta_{e}+\gamma_{x z} \cdot \sin \beta_{e} \cdot \cos \beta_{e} \\
& \sigma_{r}=\sigma_{x} \cdot \cos ^{2} \beta_{e}+\sigma_{z} \cdot \sin ^{2} \beta_{e}+2 \tau_{x z} \cdot \sin \beta_{e} \cdot \cos \beta_{e}
\end{aligned}
$$

Otherwise, when the bar fall in plane parallel to $\mathrm{Y}-\mathrm{Z}$ plane the strain and stress along the bar axis at the Gauss points are:

$$
\begin{gathered}
\varepsilon_{r}=\varepsilon_{y} \cdot \cos \beta_{e}+\varepsilon_{z} \cdot \sin ^{2} \beta_{e}+\gamma_{y z} \cdot \sin \beta_{e} \cdot \cos \beta_{e} \\
\sigma_{r}=\sigma_{y} \cdot \cos ^{2} \beta_{e}+\sigma_{z} \cdot \sin ^{2} \beta_{e}+2 \tau_{y z} \cdot \sin \beta_{e} \cdot \cos \beta_{e}
\end{gathered}
$$

\section{Equivalent Nodal Forces and Global Stiffness Matrix}

In the nonlinear analysis of reinforced or prestressed concrete structures, it is necessary to calculate the equivalent nodal forces at the end of each iterative step. These forces are determined from the stresses of concrete and prestressing steel by the following relations:

$$
\begin{aligned}
& \left\{F_{c}\right\}=\int_{-1}^{+1} \int_{-1-1}^{+1+1} \int_{-1}[B]^{T} \cdot\left\{\sigma_{c}\right\} \cdot|J| \cdot d \zeta \cdot d \eta \cdot d \xi \\
& \left\{F_{e}\right\}=\int_{-1}^{+1}[B]^{T} \cdot\{\sigma\} \cdot|J| \cdot A_{e} \cdot d r
\end{aligned}
$$

Where $\left\{F_{c}\right\}$ is the equivalent nodal forces that result from the concrete stresses $\left\{\sigma_{c}\right\}$ and $\left\{F_{e}\right\}$ is the equivalent nodal forces that result from the stresses of prestressing tendon or steel bar $\{\sigma\}$.

Global stiffness matrix is the sum of the stiffness contribution of concrete, steel and prestressing tendons: 


$$
[K]=[K]_{c}+[K]_{s}+[K]_{e}
$$

\section{Material Modelling:}

Since nonlinear finite element analysis of reinforced concrete structure is computationally expensive, a simplified and efficient models are required to simulate the material behavior. However, these models should adequately predict the overall behavior of the concrete members. Realistic modeling of material behavior is very essential to predict the nonlinear response during any stage of loading and the ultimate load as well.

\section{Behaviour of Concrete in Compression:}

The accuracy of predicting the nonlinear behavior of reinforced concrete members depends mainly on the adopted material models. In the present work, the behavior of concrete in compression is simulated by an elasto-plastic response up to yield limit followed by a perfectly plastic response terminated at the onset of crushing. The plasticity model is expressed in terms of the yield criterion, hardening rule, flow rule and crushing condition. The yield function used in the present work is based on the mean or normal stress invariant $I_{1}$ and shear stress invariant $J_{2}$, which are proved to be adequate for most practical applications[6]. The adopted yield function that has been widely used in the nonlinear analysis of reinforced concrete structures [7] can be expressed as:

$$
f\left(I_{1}, J_{2}\right)=\left[\alpha I_{1}+3 \beta J_{2}\right]^{0.5}=\sigma_{o}
$$

Where $\alpha$ and $\beta$ are two material parameters and $\sigma_{\boldsymbol{o}}$ is the effective stress. Based on the failure envelope of plain concrete under biaxial compression obtained from the experimental results of Kupfer et.al [8], the parameters $\alpha$ and $\beta$ will take the values, $0.355 \sigma_{o}$ and 1.355 respectively. A value $\sigma_{O}=0.3 f_{c}^{\prime}$ is used to defines the initial yield surface, which define the limits of initiation of elasto-plastic behavior. To establish the stress-strain relation in the plastic range, the normality of the plastic strain increment vector to the yield surface is commonly used as a flow rule. The incremental plastic strain vector, that is normal to the yield surface, can be expressed as:

$$
\{d \varepsilon\}_{p}=d \lambda \cdot \frac{\partial f(\sigma)}{\partial \sigma}=d \lambda \cdot\{\bar{a}\}
$$

In which $d \lambda$ is a proportional constant which determines the magnitude of the plastic strain increment. The flow vector $\{\bar{a}\}$ is defined as the derivatives of the yield function given in Eq.(27) with respect to the stress components and is given by:

$$
\{\bar{a}\}^{T}=\left[\frac{\partial f}{\partial \sigma_{x}}, \frac{\partial f}{\partial \sigma_{y}}, \frac{\partial f}{\partial \sigma_{z}}, \frac{\partial f}{\partial \tau_{x y}}, \frac{\partial f}{\partial \tau_{x z}}, \frac{\partial f}{\partial \tau_{y z}}\right]
$$

The hardening rule is required to define the change of the loading surface during the plastic deformation. An isotropic hardening rule has been adopted in the present study. The subsequent loading functions may be expressed from Eq.(27) as:

$$
f(\sigma)=\text { C. } I_{1}+\left[\left(\text { C } . I_{1}\right)^{2}+3 \beta . J_{2}\right]^{0.5}=\sigma_{o}
$$


In the present work, the equivalent uniaxial stress-strain relationship beyond the elastic limit (when $\sigma_{\boldsymbol{o}}$ exceeds $0.3 f_{c}^{\prime}$ ) which represents the work-hardening stage behavior, is represented by a quarter circle which is shown in Fig(2). In this region the relation between the effective stress $\sigma_{\boldsymbol{o}}$ and plastic strain $\varepsilon_{p}$ may be written as [9]:

$\sigma_{o}=f_{c}^{\prime}\left[0.3+0.7\left\{\left(2 \frac{\varepsilon^{\prime}-\frac{\sigma^{\prime}}{E_{c}}}{\varepsilon_{p, \max }^{\prime}}\right)-\left(\frac{\varepsilon^{\prime}-\frac{\sigma^{\prime}}{E_{c}}}{\varepsilon_{p, \max }^{\prime}}\right)^{2}\right\}^{0.5}\right]$

Where $E_{c}$ is the initial elastic modulus of concrete and $\varepsilon_{p, \max }^{\prime}=\varepsilon_{o}-\frac{f_{c}^{\prime}}{E_{c}}$, $\varepsilon o$ is the strain at peak stress $f_{c}^{\prime}$. The hardening parameter is obtained by differentiating Eq.(31) with respect to the plastic strain ( $\varepsilon p$ ) which result in:

$H^{\prime}=\frac{d \sigma_{o}}{d \varepsilon_{p}}=0.7 \frac{f_{c}^{\prime}}{\varepsilon_{p}}\left[1-\frac{\varepsilon_{p}}{\varepsilon_{p, \text { max }}^{\prime}}\right]\left[\frac{2 \varepsilon_{p, \text { max }}^{\prime}-1}{\varepsilon_{p}}\right]^{-0.5}$

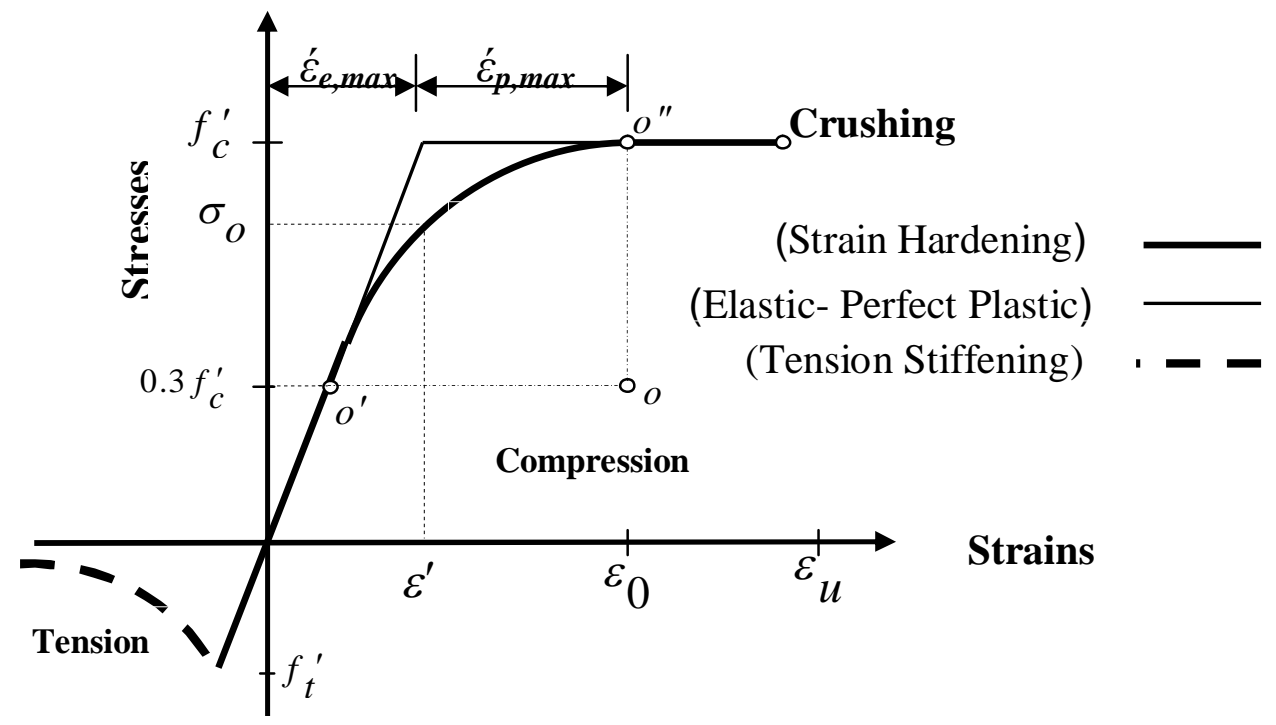

Fig. (2) Representation of concrete equivalent uniaxial stress-strain curve.

The crushing type of concrete fracture is a strain controlled Phenomenon. In the present work the same yield function has been used to define the limit of crushing condition by expressing the yield function in terms of strain components instead of stress components as follows [7]:

$\alpha I_{1}^{\prime}+3 \beta J_{2}^{\prime}=\varepsilon^{2}$ 
Where $I_{1}^{\prime}, J_{2}^{\prime}$ are the strain invariant and $(\varepsilon)$ is the equivalent uniaxial strain. When the equivalent uniaxial strains reach the crushing strain $\left(\varepsilon_{u}\right)$, that can be extrapolated from uniaxial compression test, the concrete is assumed to crush and lose all its strength and stiffness.

\section{Behavior of Concrete in Tension:}

Prior to cracking, the behavior of concrete in tension is modeled as linear elastic material. The adopted cracking behavior is described in terms of strain criterion. If the maximum principal strain exceeds a limiting value $\left(\varepsilon_{c r}=f^{\prime} / E_{\mathbf{c}}\right)$, a crack is assumed to develop in a plane orthogonal to the axis of major principal tensile strain. A maximum of two orthogonal cracks are allowed to form at each sampling point. The post cracking tension stiffening and shear retention are also considered. The adopted concept of tension-stiffening is based on the fact that the concrete between the cracks due to the bond action between the steel bar and the surrounding concrete can carry tension stresses. In the present work an exponential function [10] shown in Fig. (3) is used to simulate this effect as follows:

$$
\sigma=f_{t}^{\prime}\left\lfloor\exp \left[-\left(\varepsilon-\varepsilon_{c r}\right) / \mu\right\rfloor\right.
$$

Where:

$f_{t}^{\prime}$ is the tensile strength of concrete.

$\varepsilon_{c r}$ is the cracking strain $=f_{t}^{\prime} / E_{c}$.

$\varepsilon \quad$ is the tensile strain normal to the plane of cracking.

$\mu \quad$ is the softening parameter, which depends on the fracture energy [10].

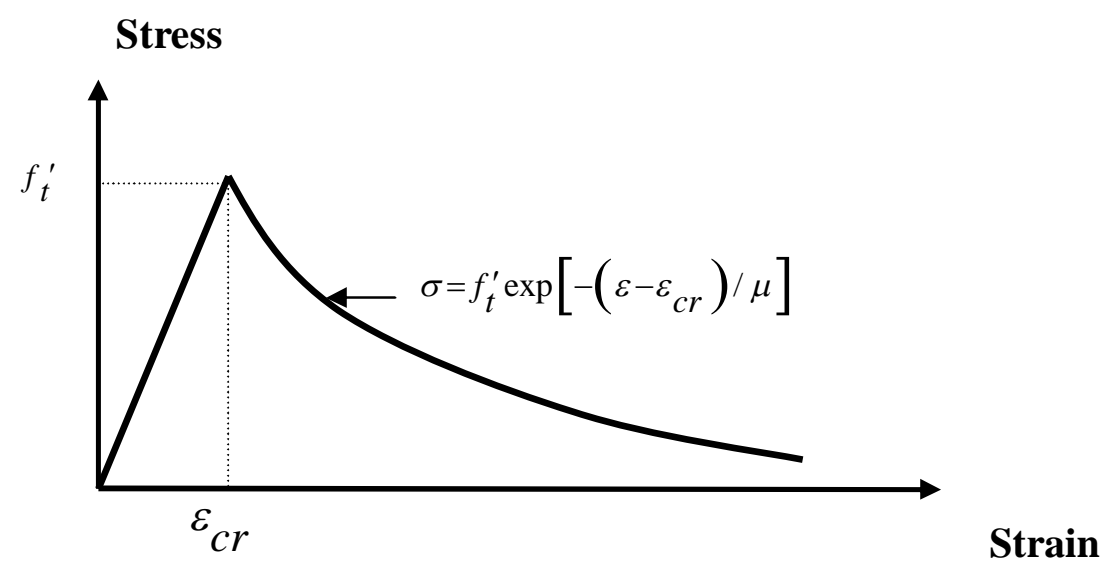

Fig. (3) Tension stiffening model for cracked concrete.

Experimental studies [6] has shown that a considerable amount of shear stress can be transferred through the rough surface of the plane of the crack. In the present work, a reduced shear modulus $\beta_{1} G_{o}$ has been used to model the reduced shear modulus of the cracked concrete.

Where $G_{o}$ is the elastic shear modulus and $\beta_{1}$ is a shear retention factor which range from $(0.0)$ to(1.0) and in the present study the adopted value is taken equal to (0.5). 


\section{Material Modeling of Prestressing Steel:}

The shape of the stress-strain curve of prestressing steel differs from that of reinforcing steel in that no definite yield plateau or point can be identified. In this work a multi-linear curve shown in fig. (4) has been used. It is assumed that the prestressing steel will be in a tension state only and thus the compression branch of the curve is not considered.

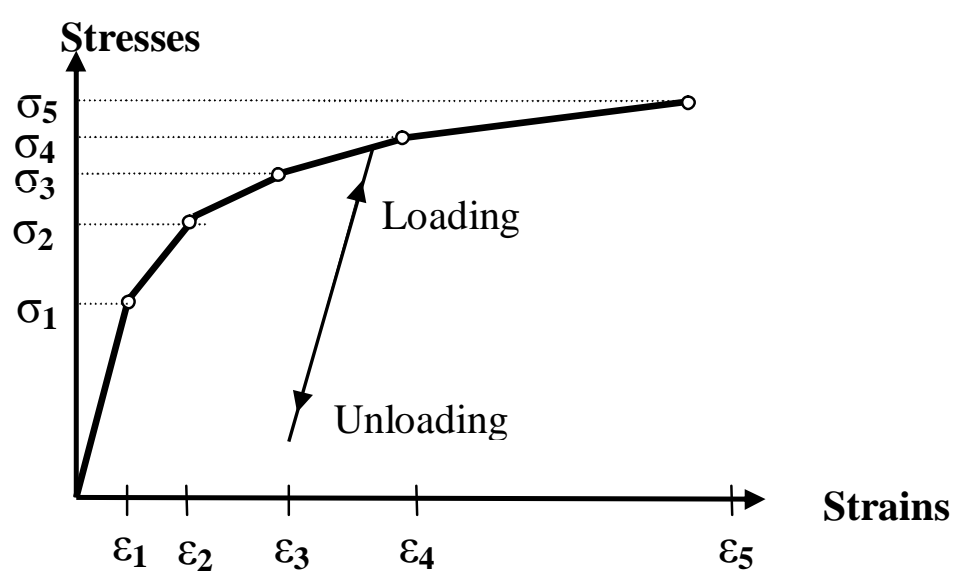

Fig. (4) Stress-Strain curve for prestressing steel.

\section{Numerical Examples:}

i- Shaikh and Branson Prestressed Concrete Beam

The simply supported prestressed concrete beam tested by Shaikh and Branson [11] was selected for the analysis using the developed computer program. This beam was loaded by central point load. The material properties are listed in table (1). The geometry and loading conditions for this beam are shown in Fig. (5). Making advantage of symmetry, only half of the beam is idealized by 14 brick elements as shown in Fig. (6). The prestressing steel is represented by 7 embedded bars, one bar in each of the lower brick elements, located at its real position. In Fig. (7) the predicted load deflection curve at midspan of the beam is compared with the experimented one. The figure shows a good agreement with the test results.

Table (1): Material Properties of Shaikh and Branson Beam [11].

\begin{tabular}{|c|c|}
\hline Concrete & Prestressing Steel \\
\hline $\begin{array}{l}\text { Young's Modulus } E_{c}=31500.0 \mathrm{MPa} \\
\text { Ult. Comp. Stress } f_{c}^{\prime}=45.0 \mathrm{MPa} \\
\text { Ult. Tens. Stress } \quad f_{t}^{\prime}=4.3 \mathrm{MPa} \\
\text { Ult. Comp. Strain } \quad \varepsilon_{u}=0.0035 \\
\text { Poisson's Ratio } \quad v=0.18\end{array}$ & $\begin{array}{l}\text { Elastic Modulus } E_{p s}=200000.0 \mathrm{MPa} \\
\text { Yield Stress } \quad f_{p y}=1820.0 \mathrm{MPa} \\
\text { Ult. Stress } \quad f_{p u}=2100.0 \mathrm{MPa} \\
\text { Effective Prestressing Stress } \\
\qquad \sigma_{o p}=1340.0 \mathrm{MPa} \\
\text { Area of Prestressing Steel }{ }_{p s}=71.3 \mathrm{~mm}^{2}\end{array}$ \\
\hline
\end{tabular}




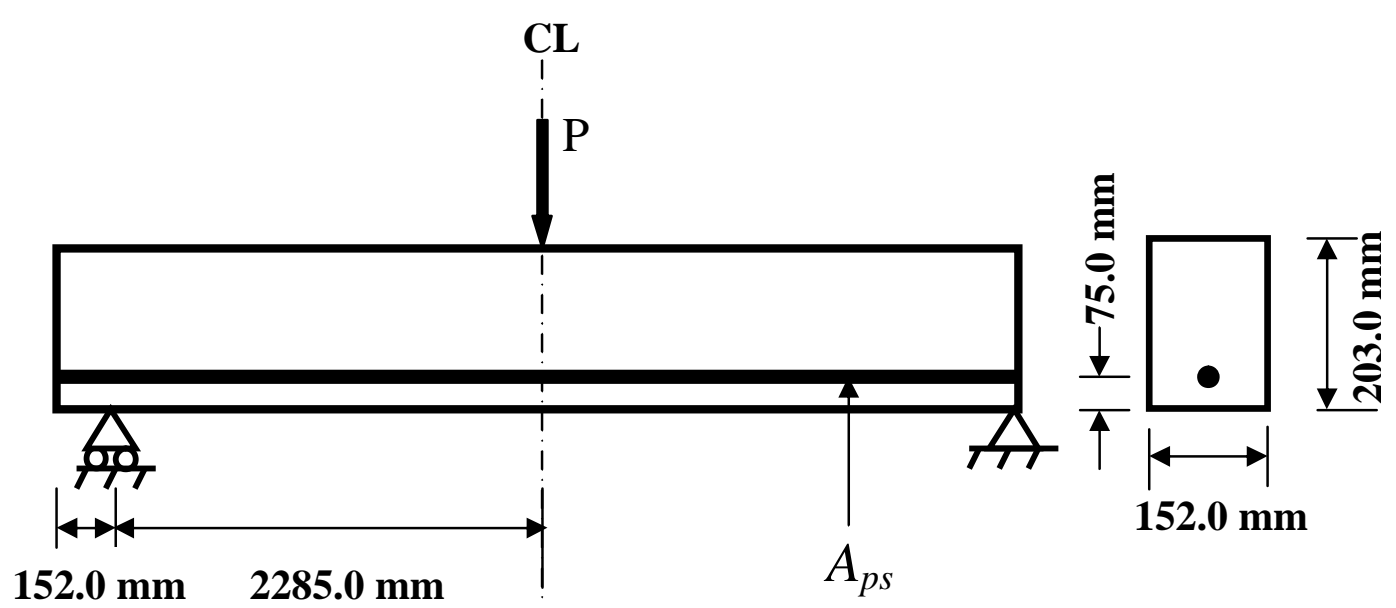

Fig. (5) Geometry and loading condition for Shaikh and Branson bean

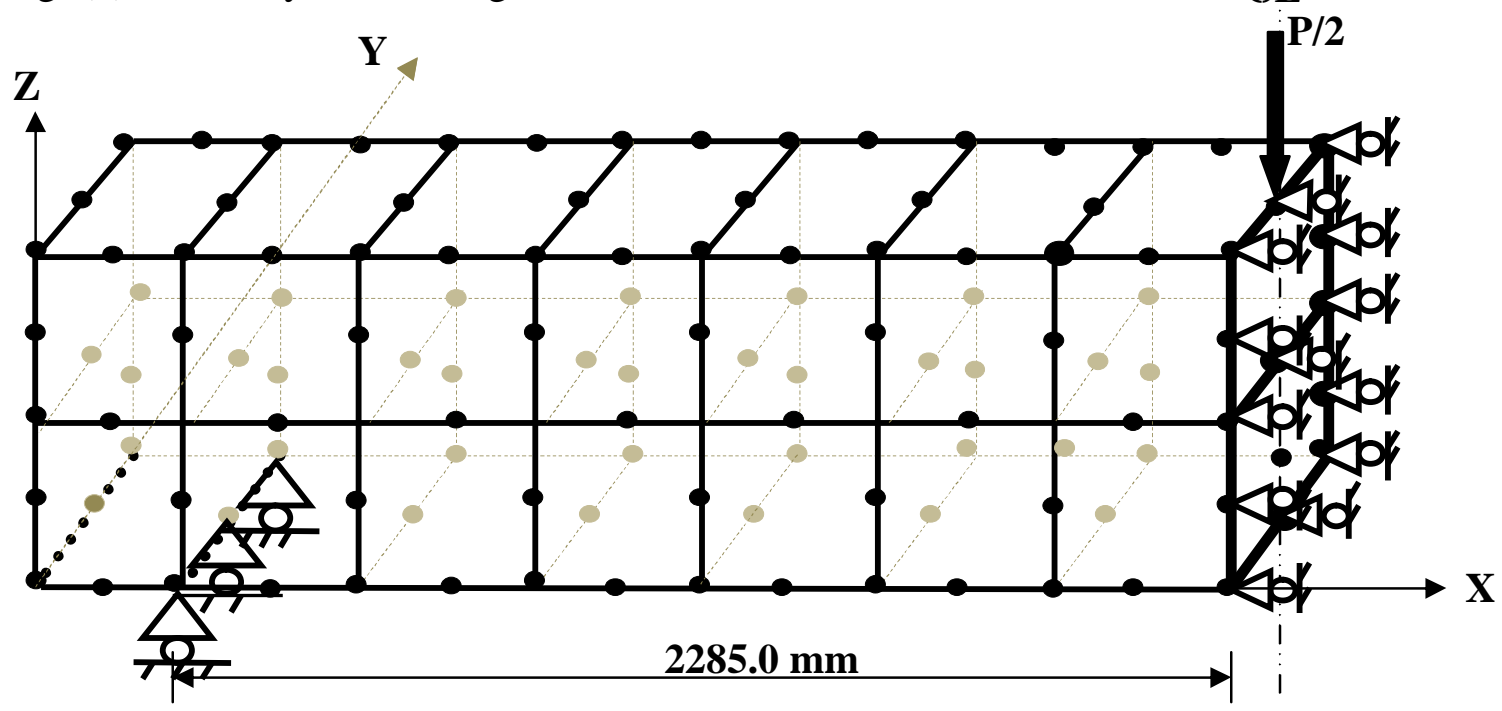

Fig. (6) 3-D finite element idealization Shaikh and Branson beam[11]

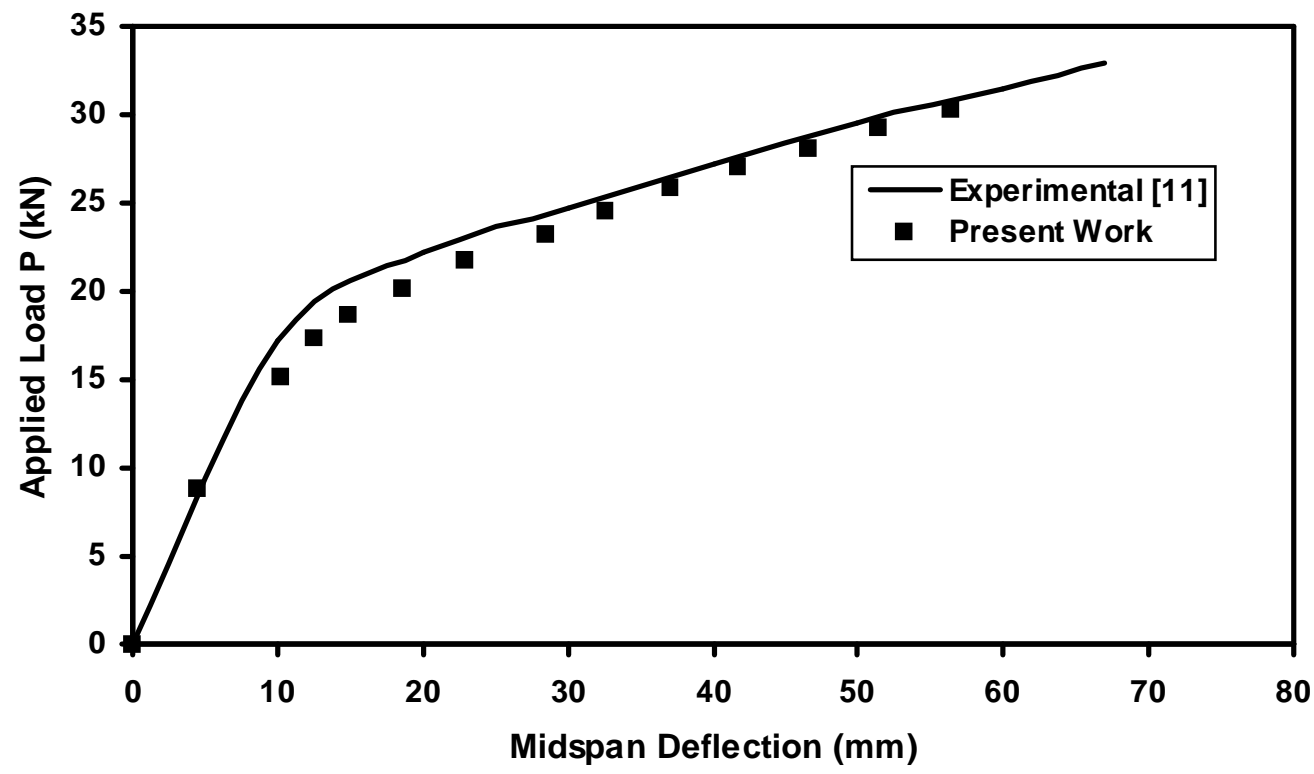

Fig. (7) Load-Deflection Curve for Shaikh and Branson beam[11]. 


\section{ii- Lin Continuous Prestressed Concrete Beam}

Lin [12] tested a series of continuous prestressed concrete beams under static and repeated loads up to failure. Beam (A) was selected to validate the correctness of the proposed formulation. The geometry and loading conditions for this beam are shown in Fig. (8) while the material properties are listed in table (2). Taking advantage of symmetry of the beam and loading, half of the beam has been idealized by 14 brick elements. Figure (9) shows the idealization of the prestressing steel as an embedded bar, while table (3) shows the cartesian coordinates of the nodes of the embedded bar elements. The predicted midspan load-deflection curve due to the external applied load is compared with the experimental results are shown in Fig. (10). The failure load obtained from the analysis is equal to $(167.1 \mathrm{kN})$ accompanied by crushing of concrete near the central support. This is in good agreement with the experimental ultimate load $(155.8 \mathrm{kN})$ that reported in reference [12].

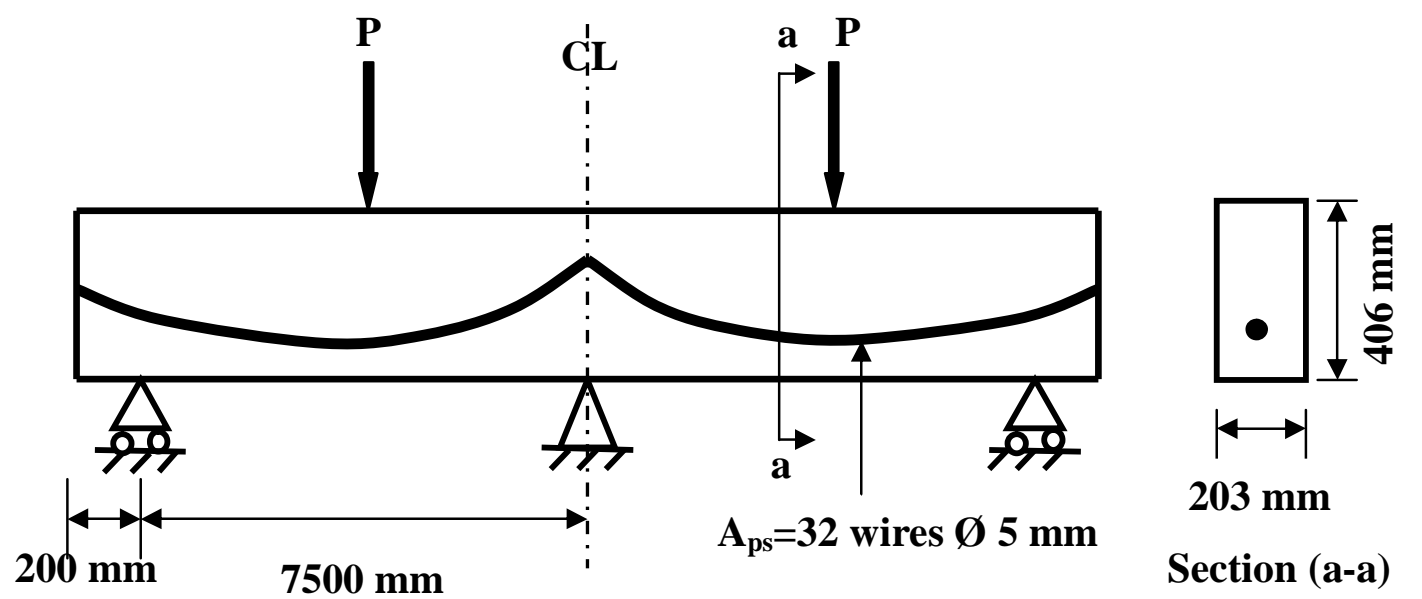

Fig. (8) geometry and loading condition for Lin beam [12].

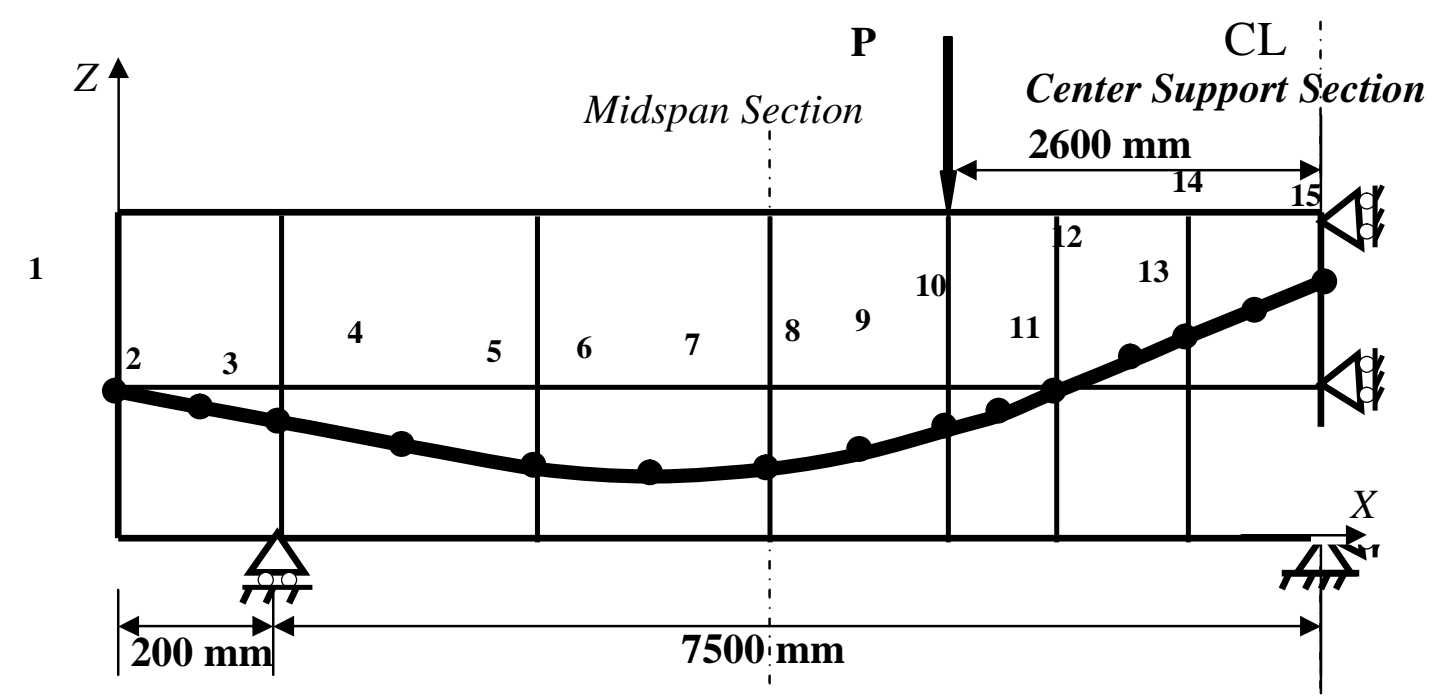

Fig. (9) Finite element and embedded bar idealization. 
Table (2): Material Properties of Lin Beam [12].

\begin{tabular}{|c|c|}
\hline Concrete & Prestressing Steel \\
\hline Young's Modulus $E_{c}=36500.0 \mathrm{MPa}$ & Elastic Modulus $E_{p s}=200000.0 \mathrm{MPa}$ \\
\hline Ult. Comp. Stress $f_{c}^{\prime}=35.0 \mathrm{MPa}$ & $f_{p y}=1480.0 \mathrm{MPa}$ \\
\hline Ult. Tens. Stress $f_{t}^{\prime}=6.3 \mathrm{MPa}$ & Ult. Stress $\quad f_{p u}=1600.0 \mathrm{MPa}$ \\
\hline Ult. Comp. Strain $\varepsilon_{u}=0.003$ & Effective Prestressing Stress \\
\hline Poisson’s Ratio & $\sigma_{o p}=827.0 \mathrm{MPa}$ \\
\hline & Area of Prestressing Steel $A_{p s}=621.3 \mathrm{~mm}^{2}$ \\
\hline
\end{tabular}

Table (3): Cartesian Coordinates of the Embedded Bar for Lin Beam.

\begin{tabular}{|c||c||c||c|}
\hline Node & $\mathbf{X}(\mathbf{m m})$ & $\boldsymbol{Y}(\mathbf{m m})$ & $\mathbf{Z}(\mathbf{m m})$ \\
\hline \hline 1 & 0.0 & 101.5 & 203.00 \\
\hline 2 & 100.0 & 101.5 & 202.00 \\
\hline 3 & 200.0 & 101.5 & 201.10 \\
\hline 4 & 1125.0 & 101.5 & 191.90 \\
\hline 5 & 2050.0 & 101.5 & 182.90 \\
\hline 6 & 2975.0 & 101.5 & 173.80 \\
\hline 7 & 3900.0 & 101.5 & 164.70 \\
\hline 8 & 4500.0 & 101.5 & 158.80 \\
\hline 9 & 5100.0 & 101.5 & 153.00 \\
\hline 10 & 5571.0 & 101.5 & 178.00 \\
\hline 11 & 6042.0 & 101.5 & 203.00 \\
\hline 12 & 6456.5 & 101.5 & 225.00 \\
\hline 13 & 6871.0 & 101.5 & 247.00 \\
\hline 14 & 7285.5 & 101.5 & 269.00 \\
\hline 15 & 7700.0 & 101.5 & 291.00 \\
\hline
\end{tabular}

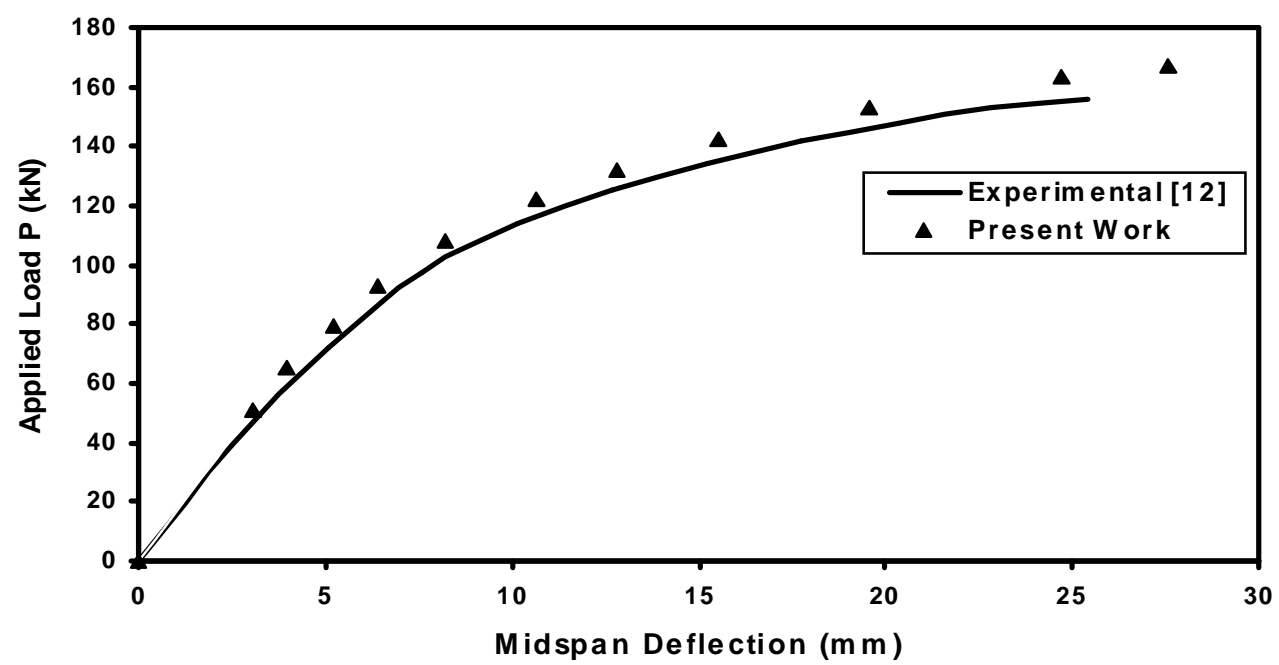

Fig. (10) Load-Deflection Curve for Lin beam [12]. 


\section{Conclusions:}

The paper presented a general formulation of the embedded bar in a brick concrete element to facilitate a three dimensional analysis of prestressed concrete beams. The developed model is proved to be suitable to predict the behavior of the prestressed concrete beams. Two test examples have been chosen to demonstrate the applicability of the model for the nonlinear analysis of prestressed concrete beams. The predicted results, in terms of load-deflection curves and failure load had shown a good agreement with the experimental results.

\section{References}

1. Phillips, D.V. and Zienkiewicz, O.C., "Finite Element Nonlinear Analysis of Concrete Structures", Journal of the Institution of Civil Engineers Proceedings, Part 261(3), 1976, pp. 59-88.

2. Krishnamoorthy, C.S. and Panneerselvam, A., "A Finite Element Model for the Nonlinear Analysis of Reinforced Concrete Framed Structures", Journal of Structural Engineering (London), Vol.55, 1977, pp. 331-338.

3. Elwi, A.E., and Hurdy, T.M., "Finite Element Model for Curved Embedded Reinforcement", Journal of Engineering Mechanics Division, Proceedings, ASCE, Vol. 115, 1989, pp. 740-754.

4. Mahmood, M.N., "Formulation of Embedded Reinforced bar in General Shell Element", Scientific Journal of Tikrit University, Vol. 8, No. 3, September 2001, pp. 2437.

5. Zienkiewics, O.C., "The Finite Element Method", McGraw-Hill, Third Edition, London, 1977.

6. Chen, W.F., "Plasticity in Reinforced Concrete", McGraw-Hill, New - York, 1982.

7. Hinton, and E., Owen, D.R.J., "Finite Element Software for Plates and Shells", Pineridge press Limited, Swansea, U.K., 1984.

8. Kupfer, H., Hilsdorf, K.H., and Rush, H., "Behaviour of Concrete Under Biaxial Stresses", ACI Journal, Proceedings, Vol. 66, No. 8, August 1969, pp. 656-666.

9. Embabi, M.S., and Cope, R.J., "An Equivalent Elasto-Plastic Constitutive Model for Biaxially Loaded Concrete", Proceeding of International Conference on Computer Aided Analysis and Design of Concrete Structures, Pineridge Press Limited, Swansea, 1984, pp. 275-288.

10. Jiang, J.J., "Finite Element Techniques for Static Analysis of Reinforced Concrete Structures", Invited Paper at International Conference on Computer Aided Analysis and Design of Concrete Structures, Split, Yugoslavia, September, 1984.

11. Shaikh, A.F. and Branson, D.E., "Non-Tensioned Steel in Prestressed Concrete Beams", PCI Journal, Vol. 15, No. 1,February 1970, pp. 14-36.

12. Lin, T.Y., "Strength of Continuous Prestressed Concrete Beams under Static and Repeated Load", ACI Journal, Proceedings, Vol. 26, No. 10, 1955, pp. 1037-1058. 